\title{
Simulating kangaroo farming: extending GRASP to include kangaroo population density simulation.
}

\author{
P.D. Moloney $^{\text {a }}$, J.W. Hearse ${ }^{\text {a }}$ \\ ${ }^{a}$ School of Mathematical and Geospatial Sciences, RMIT University, GPO BOX 2476, Melbourne, \\ Victoria, Australia, 3001

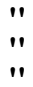 \\ Email: paul.moloney@rmit.edu.au \\ Abstract: It has been argued that converting some production in semi-arid rangelands from beef and wool \\ to kangaroo commodities would have beneficial ecological and environmental consequences (Wilson and \\ Edwards, 2008). The kangaroos ability to react to changes in weather could be used to mitigate the affect \\ of droughts and post-drought recovery in marginal areas. Income from kangaroo harvesting during and \\ after a drought could financially counter restocking costs of domestic animals, providing an incentive for \\ landholders to consider diversifying into kangaroos.
}

A model was constructed to explore changes in kangaroo levels over time for a landholder farming kangaroos. The model developed uses a physiological structured population model (PSPM) in conjunction with GRASP to assess kangaroo population densities and harvest quantities. GRASP simulates the effect of weather, soil condition, and stocking rates of either cattle or sheep and the associated production of beef or wool. It does this diurnally through estimating the total standing dry matter ( $t s d m)$. GRASP has been validated for large sections of semi-arid rangelands in New South Wales and Queensland (Littleboy and McKeon, 2005).

Historical and simulated weather was used in simulations to analyse the model. The model was run using the previously included species of cattle, sheep as well as kangaroos. Comparisons were made between forage utilisation of the different species used for each commodity produced, beef, kangaroo meat, and wool. The comparisons were made using dry sheep equivalents (dse). The results in this study are in agreement with the most recent analysis on kangaroo dse (Munn et al., 2009). It is noted that the current kangaroo $d s e$ figure, with which this study concurs, is approximately half the figure that landholders often use (Grigg, 2002; Munn et al., 2009).

The simulated commodity production resulted in greater production from cattle in semi-arid rangelands. Implying that any financial analysis may favour cattle, unless the commodities from sheep and kangaroo have a much larger per unit value. This study highlights the impact of high juvenile mortality of kangaroos (Dawson, 1995) and endeavours to make harvesting a commercially viable option for landholders.

Keywords: Rangelands, kangaroo, GRASP, physiological structured population model 


\section{INTRODUCTION}

Currently semi-arid Australian rangeland properties produce mainly beef and wool on marginal lands. A major area of concern is grazing pressure. Kangaroos are considered to have a considerable impact on grazing pressure, and for that reason they are often considered pests by landholders (Grigg, 2002). It has been thought that converting from farming European stock to native wildlife would have environmental benefits (Wilson and Edwards, 2008). The commercial benefits from the change are unclear. Kangaroo (and wallaby) harvesting is controlled by state and federal governments, generally under a quota system (Pople and Grigg, 1999).

With rapid increase in kangaroo numbers after a drought has broken (Dawson, 1995), the kangaroos ability to react to changes in weather could be used to mitigate the affect of droughts and post-drought recovery in marginal areas (Moloney et al., 2011). To fully explore grazing of kangaroos after drought has broken a model that responds to environmental factors such as weather and soil condition needs to be used. The dynamics are important. When forage is scarce, and fodder has to be bought to maintain stock, the pest value of kangaroos is at its highest (Pople and Grigg, 1999). When forage is plentiful landholders are not concerned by kangaroo numbers. There can be so much forage it cannot be efficiently utilised (Caughley et al., 1987).

GRASP can simulate the effect of weather, soil condition, stocking rates for either cattle or sheep and the associated production of beef or wool (Littleboy and McKeon, 2005). This study extends the GRASP model to include the ability to simulate kangaroo population dynamics. The notation used in the kangaroo population model is collated in Table 1

\section{The Kangaroo Population Model}

GRASP converts beasts/ha and weaner equivalents when calculating the amount of each forage type eaten. This may be acceptable when the conversion rates between sheep and cattle are known. However, the dse of kangaroos is in dispute Grigg (2002); Munn et al. (2009). Therefore it is more appropriate to work entirely in kangaroos for the kangaroo simulations. The kangaroo population model is based on a previous physiological structured population model (Hacker et al., 2003). The model includes the effect of environmental conditions on the development and mortality of the kangaroo population. This enables dynamic feedback into the system so as to better simulate the effect of nutritional intake on the mammals. The current population of each gender is described via (1) and (2).

$$
\begin{aligned}
\frac{\mathrm{d} N_{\text {gender }, i}}{\mathrm{~d} t} & =-\mu\left(\text { age }_{i}, \operatorname{cond}(\text { gender }, i)\right) N_{f, i}-\operatorname{Harv}(\text { gender }, i) \\
\frac{\mathrm{d} W t_{\text {gender }, i}}{\mathrm{~d} t} & =g\left(\text { gender }, \text { age }_{i}, \operatorname{cond}(\text { gender }, i)\right)
\end{aligned}
$$

In addition to equations above, (3) to (5) are boundary conditions required for each new cohort. These equations relate to the establishment of the new cohorts (births) in the next time period. At the beginning of each time period the existing cohorts must also be updated as given by (6) to (7). In the following equations $T_{n+1}^{-}$and $T_{n+1}^{+}$represent the time just before and just after $T_{n+1}$.

$$
\begin{aligned}
N_{f, 0}\left(T_{n+1}^{+}\right) & =\sum_{i=0}^{Q-1} b\left(\text { age }_{i}, \text { cond }\right) N_{f, i}\left(T_{n+1}^{-}\right) \\
N_{m, 0}\left(T_{n+1}^{+}\right) & =s N_{f, 0}\left(T_{n+1}^{+}\right) \\
W t_{\text {gender }, 0}\left(T_{n+1}^{+}\right) & =W t_{0} \\
N_{\text {gender }, i+1}\left(T_{n+1}^{+}\right) & =N_{\text {gender }, i}\left(T_{n+1}^{-}\right) \\
W t_{\text {gender }, i+1}\left(T_{n+1}^{+}\right) & =W t_{\text {gender }, i}\left(T_{n+1}^{-}\right)
\end{aligned}
$$

Age related mortality has been previously modelled (Hacker et al., 2003) using a Weibull survival function (8). The functional response (9) has been estimated by Caughley et al. (1987), and, was also used to 
Table 1. Symbols used in the kangaroo population model.

\begin{tabular}{|c|c|}
\hline Notation & Definition \\
\hline$N_{f, i}, N_{m, i}$ & The population of in cohort $i$, females and males respectively ( $d s e / h a$. \\
\hline$V$ & The total standing dry matter (vegetation) available $(\mathrm{kg} / \mathrm{ha})$ \\
\hline$a g e_{i}$ & The mean age of the members of cohort $i$ (years). \\
\hline$\mu\left(a g e_{i}, V\right)$ & The mortality rate based on the age and forage available $(\% /$ year $)$. \\
\hline $\operatorname{Harv}\left(\right.$ gender, $\left.a g e_{i}\right)$ & $\begin{array}{l}\text { The harvest rate based on the age and gender of the cohort } \\
\text { (kangaroos/year). }\end{array}$ \\
\hline$W t($ gender,$i)$ & Average weight of the animals in that cohort, by gender $(\mathrm{kg})$. \\
\hline$g\left(\right.$ gender, age $\left._{i}, V\right)$ & $\begin{array}{l}\text { The function of weight gain given the forage available and the gender } \\
\text { and age of the animal }(\mathrm{kg} / \text { year }) \text {. }\end{array}$ \\
\hline$b\left(a g e_{i}, V\right)$ & $\begin{array}{l}\text { The birth rate for that group, given their ages, and available forage } \\
\text { (kangaroos/year). }\end{array}$ \\
\hline$T_{n}$ & The point at which the $n^{t h}$ new cohort is established (years). \\
\hline$s$ & The primary sex ratio at birth (dimensionless). \\
\hline $\operatorname{Intake}(V, W t)$ & $\begin{array}{l}\text { The function for the daily intake of forage for a member of the group, } \\
\text { given their weight }(\mathrm{kg} / \mathrm{day}) \text {. }\end{array}$ \\
\hline $\operatorname{cond}($ gender,$i)$ & $\begin{array}{l}\text { The condition of the group, by gender and cohort, includes a delayed } \\
\text { effect (dimensionless). }\end{array}$ \\
\hline delay & The time delay for the groups condition (years). \\
\hline satiation & $\begin{array}{l}\text { The amount of available forage required for the animal to be satiated } \\
(\mathrm{kg} / \mathrm{day}) \text {. }\end{array}$ \\
\hline peaten $(t)$ & $\begin{array}{l}\text { The proportion of the total desired forage actually eaten } \\
\text { (dimensionless). }\end{array}$ \\
\hline desire $(t)$ & The total amount desired to be eaten based on the available forage $(\mathrm{kg})$. \\
\hline$\gamma$ & The overall harvest rate for the species $(\% /$ year $)$. \\
\hline refuge & The minimum kangaroo density (kangaroos/ha). \\
\hline pre $f_{\text {gender }}$ & The harvest bias for the given gender (dimensionless). \\
\hline$H($ gender,$i)$ & $\begin{array}{l}\text { An indicator function for whether that gender and cohort is harvestable } \\
\text { (dimensionless). }\end{array}$ \\
\hline
\end{tabular}

determine condition. The condition of the cohort of kangaroos is estimated via a goal gap formulation (10), with the instantaneous condition (11). There is a delay term in the differential equation as it has been noted that the change in condition of kangaroos has an approximately 3 month delay related to a change in forage (Caughley et al., 1987; Dawson, 1995; Moss and Croft, 1999).

$$
\begin{aligned}
S(\text { age }) & =\mathrm{P}(\text { AGE }>\text { age })=e^{-(0.614 \text { age })^{0.428}}, \\
\frac{\mathrm{d} \operatorname{cond}(\text { gender }, i)}{\mathrm{d} t} & =\frac{\operatorname{condT}(\mathrm{t})-\operatorname{cond}(\text { gender }, i)}{\text { delay }} \\
\operatorname{condT} & =\frac{\text { peaten } \times \text { greeneaten } \times \text { Intake }(V, W t)}{0.88 \text { eaten } \times \text { Intake }(\text { satiation }, W t)} \\
\text { peaten }(t) & =\frac{\min \{\text {, desire }(t)\}}{\text { desire }(t)} \\
\text { desire }(t) & =\sum_{\text {gender }} \sum_{i=0}^{Q} \text { Intake }\left(V, W t_{\text {gender }, i}\right) N_{\text {gender }, i}
\end{aligned}
$$

As can be seen in Figure 1, once the available forage is greater than $300 \mathrm{~kg} / \mathrm{ha}$ the amount eaten plateaus. This can be thought of as the satiation level for the kangaroos appetite. The satiation level was then com- 


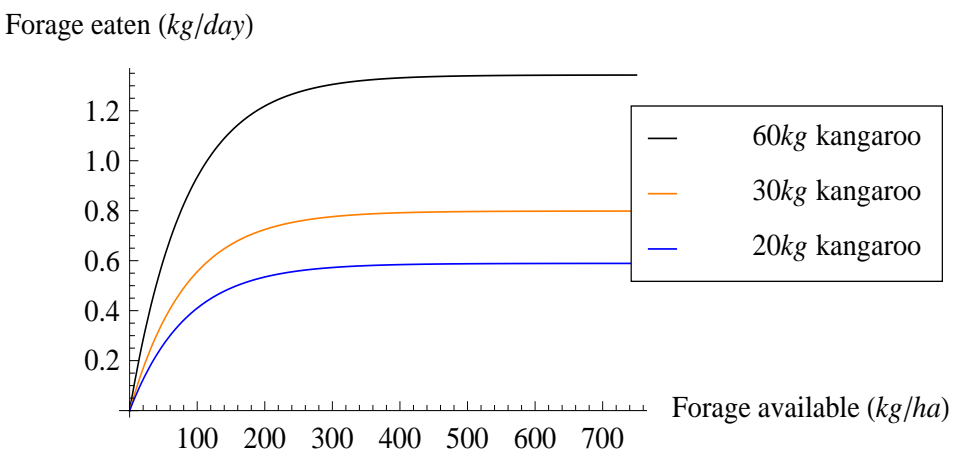

Figure 1. The functional response for a $20 \mathrm{~kg}, 30 \mathrm{~kg}$ and $60 \mathrm{~kg}$ kangaroo. That is the amount eaten $(\mathrm{kg})$ dependent on the available forage $(\mathrm{kg} / \mathrm{ha})$.

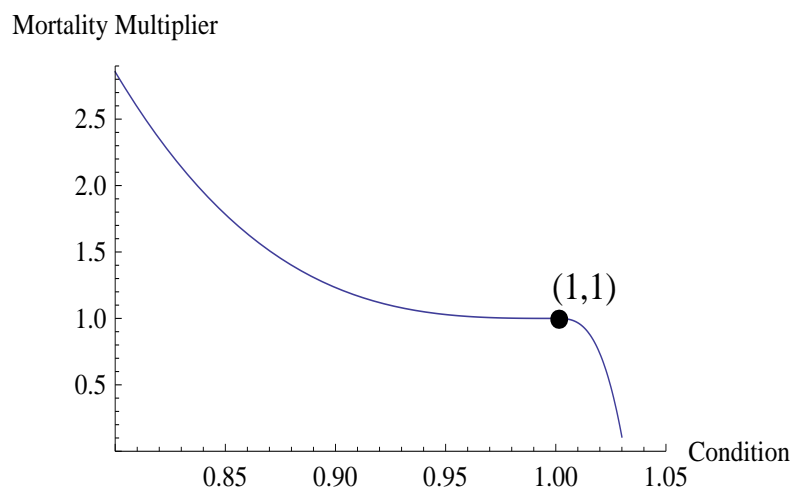

Figure 2. The mortality multiplier due to condition. When appetite is sated (condition is 1) the mortality is average. As condition decreases or increases, the mortality rate is increased and decreased respectively.

pared to the actual amount eaten, both in terms of total and green forage, to determine the instantaneous condition. It is noted that the proportion of their diet that is green (alive) is important in determining kangaroo condition (Moss and Croft, 1999). Condition in this formulation cannot exceed 1.03.

The condition is used as a measure of the mortality and fecundity functions. The better the condition of the kangaroos the lower the mortality and higher the fecundity (Caughley et al., 1987; Dawson, 1995; Moss and Croft, 1999; Pople and Grigg, 1999). For this reason, both the fecundity and mortality functions have the average fecundity and mortality multiplied by different functions of the current condition. The modelled mortality (14) of the kangaroos is the product of the mortality due to age and the effect of condition on mortality. Mortality due to age is derived as the hazard rate related to the survivorship equation (8). While the mortality related to condition is derived through the biological arguments and observations from Moss and Croft (1999) and Caughley et al. (1987). The mortality multiplier is shown inside the brackets in (14) and Figure 2.

$$
\mu(\text { age }, \text { cond })=\frac{0.34736}{a g e^{0.572}}\left(1-(\text { cond }-1)^{3} \times\left\{\begin{array}{ll}
232 & , \text { cond } \leq 1 \\
33033.5 & , \text { cond }>1
\end{array}\right)\right.
$$

The fecundity of kangaroos is modelled (15) as the product of the average fecundity given the females age and multiplier related to their condition. These were calculated from information in Caughley et al. (1987); Hacker et al. (2003). 


$$
b\left(\text { age }_{i}, \text { cond }\right)=2.724 \sqrt{\text { cond }-0.7} \begin{cases}0.4\left(\text { age }_{i}-2\right) & 2 \leq \text { age }_{i}<4 \\ 0.8 & 4 \leq \text { age }_{i}<10 \\ 0.4\left(12-\text { age }_{i}\right) & 10 \leq \text { age }_{i}<12 \\ 0 & \text { otherwise }\end{cases}
$$

Quotas and limits on kangaroo harvesting are controlled by the Government. Typically these are set to: a minimum kangaroo density of 2 kangaroos per $\mathrm{km}^{2}$; a $70 \%$ male off-take bias; and a minimum live weight of $20 \mathrm{~kg}$ (Hacker et al., 2003; Office of the Queensland Parliamentary Counsel, 2010). The harvest model for kangaroos therefore needs to include these conditions ((16) to (18)). Harvesting only occurs periodically, in this case on a monthly basis.

$$
\begin{aligned}
\operatorname{Harv}(\text { gender }, i) & =\frac{N(\text { gender }, i) \operatorname{pot}_{\text {gender }} \min \left\{1, \frac{\text { pre } f_{\text {gender }}}{1-\text { pref } f_{\text {gender }}}\right\}}{h s(\text { gender })} \\
\operatorname{pot}_{\text {gender }} & =\text { harvrate } \times \text { pref } f_{\text {gender }} \times h s(\text { gender }) \frac{\max \left\{\sum_{\text {gender }} h s(\text { gender })-\text { refuge }, 0\right\}}{\sum_{\text {gender }} h s(\text { gender })} \\
h s(\text { gender }) & =\sum_{\text {cohort } \text { gender }} H(\text { gender }, i) N(\text { gender }, i)
\end{aligned}
$$

Migration in and out of the property could have an effect on the herbivore populations. It is thought that macropods follow the structure of the ideal free distribution (IFD) (Coulson, 2009). The IFD supposes that the animals will move so that density is evenly spread across resources and can be modelled through dispersion. Given the large impact migration could have on the modelled population (Moloney and Hearne, 2009), the model assumes the surrounding land has a similar density and therefore there is no net migration.

\section{GRASP SIMULATIONS}

GRASP uses diurnal weather data to predict total standing dry matter, animal weight gain, and wool production. DataDrill interpolations for weather data from 1970 to 2010 were obtained from the Queensland Department of Environment and Resource Management (DERM) for Mitchell, Queensland. New weather data was generated for each month by bootstrapping. Simulations for cattle, sheep and kangaroo were then carried out separately, using GRASP and the same weather data. In effect it was assumed that the property was only stocking a single species in isolation. Each simulation used the same set of parameterisations for each species, with the results from the first five years removed as an initialisation period as per Littleboy and McKeon (2005).

An example of the results produced by the extended GRASP program for a single weather sequence given in Figure 3. Note that as expected, the kangaroo population falls sharply when condition is too low for too long (Figure 3a). Also note that commodity production peaks are not perfectly aligned. Finally, it is clear that by looking at the total standing dry matter $(t s d m)$ under each herbivore, that different amounts of available forage are utilised, with the kangaroos using the most and cattle the least.

A summary of the overall results of the simulations are given in Table 2. The most notable point is that production of beef is vastly greater in quantity than either of the other commodities produced, by a factor of over 10. This implies, that unless beef is much cheaper than either wool or kangaroo meat, it would seem that beef production would result in the greatest returns. The Maranoa region has seen a shift towards cattle over recent years implying that it may be more suited to cattle. The low kangaroo meat production seems to be due to the high juvenile mortality included in the model (as is seem in nature (Dawson, 1995)), causing many to die before they can be harvested. 


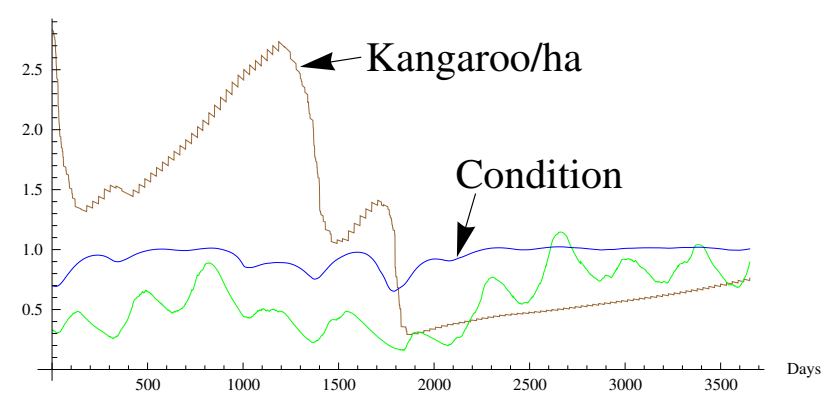

(a) Kangaroo

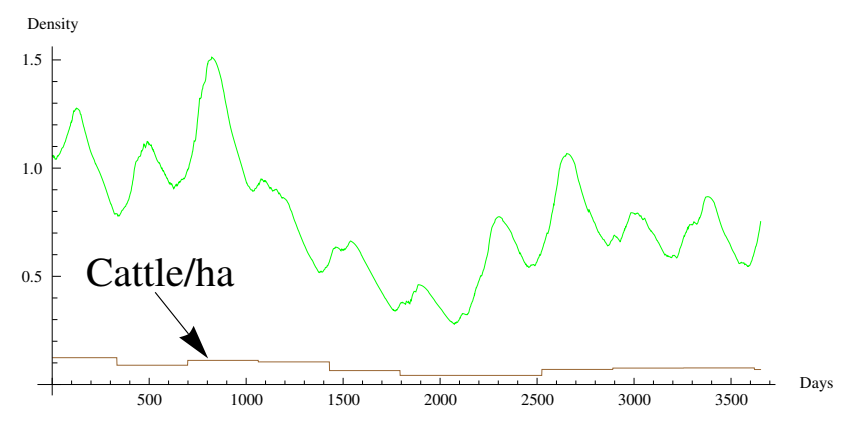

(c) Cattle

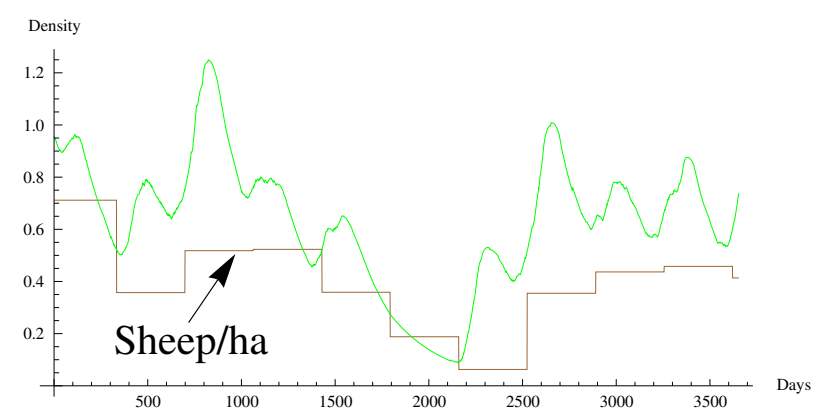

(e) Sheep

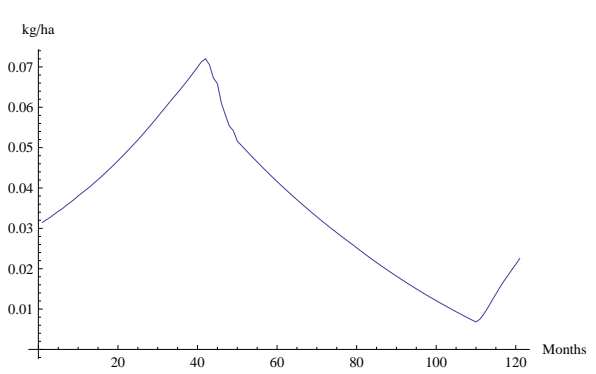

(b) Kangaroo Meat

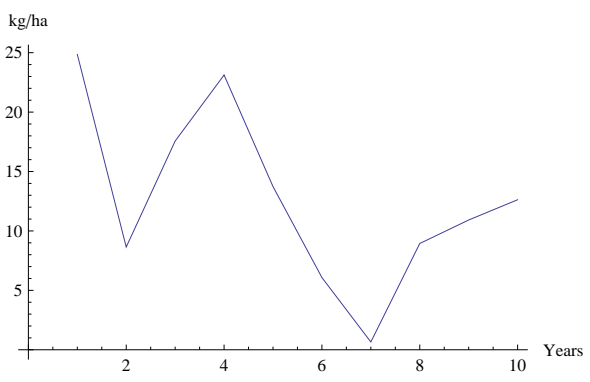

(d) Beef

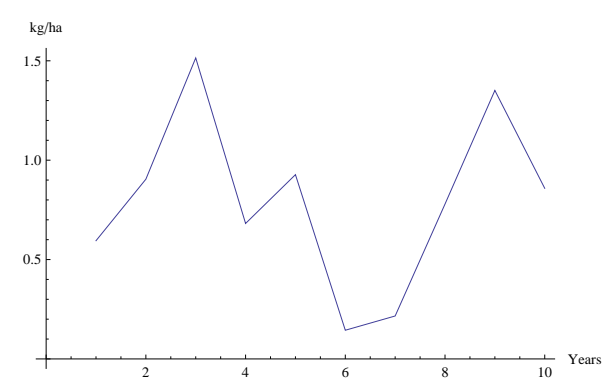

(f) Wool

Figure 3. Predictions of stocking density ( unit/ha), condition score and commodity production $(\mathrm{kg} / \mathrm{ha})$ using GRASP for (a) kangaroo, (b) kangaroo meat, (c) cattle, (d) beef, (e) sheep, and (f) wool. All predictions used the same weather data. Total standing dry mass is in green.

Table 2. Overall mean yearly herbivore density, commodity production and total standing dry matter $t s d m$ from the extended GRASP model for each herbivore.

\begin{tabular}{cccr}
\hline Herbivore & $\begin{array}{c}\text { Density } \\
\text { (Hervibore/ha) }\end{array}$ & $\begin{array}{c}\text { Commodity Production } \\
\text { (kg/ha) }\end{array}$ & $\begin{array}{c}t s d m \\
(\mathrm{~kg} / \mathrm{ha})\end{array}$ \\
\hline Cattle & 0.077 & 11.172 & 767.9 \\
Sheep & 0.410 & 0.9644 & 683.6 \\
Kangaroo & 1.694 & 0.4998 & 530.3 \\
\hline
\end{tabular}

GRASP has been validated for biomass, beef and wool production in the Maranoa region (Littleboy and McKeon, 2005). Unfortunately kangaroo population numbers have not been monitored in any detail in the area, making validation of the kangaroo model difficult. Comparing the kangaroo density to the sheep density, as well as the available forage, the effective kangaroo dse was calculated. The kangaroo 
conversion factor is in line with the most recent estimates (Munn et al., 2009) and therefore support the model.

\section{CONCLUSION}

GRASP was extended to include kangaroos. The simulations indicate that kangaroo population size can dramatically change depending on the environmental conditions, a feature which may be exploited to mitigate lost production during and post-drought. Therefore utilisation of the available forage occurs to a greater degree when conditions change. Production levels for each animal have different lags to external events. This could be partially due to the fact that domestic stock was only bought and sold annually. The analysis of the simulations from the extended GRASP model emphasised several features: the $d s e$ for kangaroos would seem to be significantly less than many landholders believe; the amount of meat produced per hectare of kangaroo on average was quite small when compared to beef or even wool production; and therefore for landholders to divert some of there potential production to kangaroo commodities would only make economic sense if their value is much greater than beef or wool.

\section{ACKNOWLEDGEMENT}

Funding for the research into mixed-grazing strategies was provided by the Rural Industries Research \& Development Corporation (RIRDC).

\section{REFERENCES}

Caughley, G., N. Shepherd, and J. Short (1987). Kangaroos, their ecology and management in the sheep rangelands of Australia. Melbourne: Cambridge University Press.

Coulson, G. (2009). Behavioural ecology of red and grey kangaroos: Caughley's insights into individuals, associations and dispersion. Wildlife Research 36(1), 57-69.

Dawson, T. J. (1995). Kangaroos: biology of the largest marsupisals. Sydney: University of New South Wales Press Ltd.

Grigg, G. C. (2002). Conservation benifit from harvesting kangaroos: status report at the start of a new millenium. In D. Lunney and C. Dickman (Eds.), A Zoological Revolution. Using native fauna to assit in its own survival, pp. 53-76. Sydney: Royal Zoological Society of New South Wales and Australian Museum.

Hacker, R. B., S. R. McLeod, and J. P. Druhan (2003). Evaluating alternative management strategies for kangaroos in the murray-darling basin: Final report. Technical report, Murray-Darling Basin Commission, Canberra.

Littleboy, M. and G. M. McKeon (2005). Appendix 2 subroutine grasp: Grass production model of evaluating the risks of pasture and land degradation in native pastures in queensland. Technical report, Rural Industries Research \& Development Corperation.

Moloney, P. D. and J. W. Hearne (2009). The population dynamics of converting properties from cattle to kangaroo production. In Proceeding of the $18^{\text {th }}$ IMACS World Congress and MODSIM09. Mathematical Simmulation Society of Australia and New Zealand.

Moloney, P. D., J. W. Hearne, I. J. Gordon, and S. R. Mcleod (2011). Portfolio optimization techniques for a mixed-grazing scenario for Australia's rangelands. Natural Resource Modeling 24(1), 102-116.

Moss, G. L. and D. B. Croft (1999). Body condition of the red kangaroo (Macropus rufus) in arid Australia: The effect of environmental condition, sex and reproduction. Australian Journal of Ecology 24(2), 97-109.

Munn, A. J., T. J. Dawson, S. R. McLeod, D. B. Croft, M. B. Thompson, and C. R. Dickman (2009). Field metabolic rate and water turnover of red kangaroos and sheep in an arid rangeland: an empirically derived dry-sheep-equivalent for kangaroos. Australian Journal of Zoology 57, 23-28.

Office of the Queensland Parliamentary Counsel (2010). Nature conservation (macropod harvest period 2011) notice 2010. Technical report, Department of Environmental and Resource Management.

Pople, A. R. and G. C. Grigg (1999). Commercial harvesting of kangaroos in Australia. Canberra: Environment Australia.

Wilson, G. R. and M. J. Edwards (2008). Native wildlife on rangelands to minimize methane and produce lower-emission meat: kangaroos versus livestock. Conservation Letters 1, 119128. 